\title{
Correction to: Endovascular management of unruptured intercostal artery aneurysms
}

\author{
Andrew K. C. Fenwick ${ }^{1 *}$, Patrick Omotoso ${ }^{2}$ and Darren Ferguson ${ }^{3}$
}

\section{Correction to: CVIR Endovasc}

https://doi.org/10.1186/s42155-018-0048-7

'In the published article (Fenwick et al., 2019) the statement under the subheading 'Consent for publication' is incorrect.

"Waived by Institutional Review Board for case reports."

should read:

"Informed consent for publication of this case report and its accompanying images has been obtained from the patient".

\section{Author details}

${ }^{1}$ Faculty of Medicine, Memorial University of Newfoundland, St. John's, Newfoundland A1B 3V6, Canada. ${ }^{2}$ Department of General Surgery, Dalhousie University, Saint John, New Brunswick, Canada. ${ }^{3}$ Department of Diagnostic Radiology, Dalhousie University, Saint John, New Brunswick, Canada.

Published online: 16 March 2020

\section{Reference}

Fenwick A, Omotoso P, Ferguson D (2019) Endovascular management of unruptured intercostal artery aneurysms. CVIR Endovasc 2:2 https://doi.org/ 10.1186/s42155-018-0048-7 